\title{
Description d'un Rhantus nouveau du Kilimandjaro (Afrique orientale)
}

[Col. Dytiscidae]

par Raymond Peschet.

Rhantus Alluaudi, n. sp. - Très allongé, parallèle, étroit, assez déprimé. Dessus alutacé brillant, réticulation fine sur la tète, plus serrée et plus forte sur le pronotum, celle des élytres à mailles plus larges, régulières; une seconde réticulation, extrèmement fine, visible dans les aréoles de la première sous un fort grossissement. Pattes, palpes et antennes testacés. Tête grande, très large, noire; labre jaune à bordure antérieure ferrugineux obscur, épistome testacé, maculé de brunàtre au milieu, couleur testacée envahissant triangulairement le front, rejoignant parfois une macule transverse arquée ferrugineuse postfrontale. Thorax transverse, déprimé, inégal, peu rétréci en avant, à strie marginale entière; angles antérieurs atteignant le bord postérieur des yeux; coloration foncière testacée, disque orné d'une large tache transverse subrectangulaire noire, également distante des quatre côtés du pronotum; base très étroitement lisérée de noir, plus largement dans le tiers médian. Élytres longs, très étroitetement ovales, subparallèles dans les trois premiers quarts, puis régulièrement arrondis, testacés, couverts de mouchetures noires, denses sur le disque jusqu'au sommet, moins serrées sur les côtés, manquant sur les deux tiers antérieurs du bord latéral et laissant en outre une ètroite bande suturale jaune bien tranchée, n'atteignant pas tout à fait le sommet de l'élytre; suture elle-mème très étroitement noire. Écusson brun, plus ou moins maculé de rougeâtre. Bord inférieur du pronotum et épipleures testacés; ceux-ci larges à la base, graduellement rétrécis jusqu'au sommet du premier segment ventral, puis nuls. Dessous noir, alutacé, peu brillant, réticulé. Pointe prosternale, hanches antérieures et intermédiaires et apophyses coxales, testacées; premier segment ventral à la base et segment anal au sommet, largement bordés de ferrugineux; segments intermédiaires étroitement bordés de même couleur à leur sommet et sur les còtés. Ailes métasternales assez étroites, rétrécies au milieu; hanches postérieures transversalement ridées.

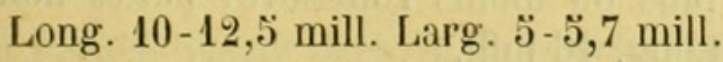

ơ. Tarses antérieurs et intermédiaires dilatés, ongles des tarses an. térieurs subégaux, le postérieur légèrement sinué; ongle antérieur des tarses intermédiaires d'un tiers plus long que le postérieur. Segment anal assez fortement strigueux. 
ๆ. Tarses antérieurs et intermédiaires simples, ongles de ces tarses ègaux, simples. Segment anal faiblement strigueux.

Nombreux exemplaires capturés au Kilimandjaro, entre 2.600 et $2.700 \mathrm{~m}$. d'altitude, dans la zone alpine des forêts supérieures, en octobre 1908, par notre confrère M. Ch. Alluadd, à qui je me fais un plaisir de dédier cette espèce.

Du groupe des espèces de montagnes à élytres allongés; voisin notamment des Rhantus advena $\mathrm{Sh}$ ar $\mathrm{p}, \boldsymbol{R}$. remator $\mathrm{Sh}$ ar $\mathrm{p}$ et $\mathrm{R}$. vicinus $\mathrm{A} u \mathrm{~b}$ é (Cordillères des Andes, Équateur, Pérou, Bolivie, 2.100 à $2.850 \mathrm{~m}$. d'altitude), il s'en distinguera très facilement pas sa forme générale bien plus parallèle, plus allongée et relativement étroite, encore accentuée par le faible rétrécissement du thorax et la grande largeur de la tète qui donne au $\boldsymbol{R}$. Alluaudi un facies analogue à celui des Lancetes américains, notamment des L. homoenyx Régimb. et L. nigriceps Er.

\section{Hétéromères nouveaux du groupe des Zonitini [CoL. Heteromera]}

par Maurice Pic.

Zonitis japonica, n. sp. - Satis elongata, subparallela, subnitida, griseo-pubescens, testacea, oculis, palpis, antennis, articulo primo excepto testaceo, tibiis tarsisque nigris.

Assez allongé, subparallèle, peu brillant, pubescent de gris, testacé avec les yeux, palpes, antennes, sauf le $1^{\mathrm{er}}$ article qui est testacé, tibias et tarses noirs, abdomen en partie roussâtre en partie rembruni. Tête courte, fortement et densément ponctuée; antennes longues et grêles, noires avec le premier article testacé; prothorax assez long, rétréci en avant, impressionné sur le disque, à ponctuation forte et plus ou moins rapprochée; écusson fortement ponctué; élytres distinctement pius larges que le prothorax, longs, faiblement élargis postérieurement, très densément ponctués, ornés de côtes faibles; dessous du corps testacé avec l'abdomen plus ou moins roussâtre; pattes noires avec les cuisses testacées. - Long. 16 mill.

Japon : Kioto (coll. Pic).

Voisin de $Z$. straminea $\mathrm{F}$ a irm.; facile à reconnaître, à première vue, par le $2^{\mathrm{e}}$ article des antennes foncé, la coloration des pattes, etc. 


\section{$2 \mathrm{BHL}$ Biodiversity Heritage Library}

1910. "Description d'un Rhantus nouveau du Kilimandjaro." Bulletin de la Société entomologique de France 1910, 89-90.

https://doi.org/10.5962/bhl.part.4664.

View This Item Online: https://www.biodiversitylibrary.org/item/38239

DOI: https://doi.org/10.5962/bhl.part.4664

Permalink: https://www.biodiversitylibrary.org/partpdf/4664

\section{Holding Institution}

Smithsonian Libraries

\section{Sponsored by}

Smithsonian

\section{Copyright \& Reuse}

Copyright Status: NOT_IN_COPYRIGHT

This document was created from content at the Biodiversity Heritage Library, the world's largest open access digital library for biodiversity literature and archives. Visit BHL at https://www.biodiversitylibrary.org. 